\title{
The Mammalian Circadian Timing System: Synchronization of Peripheral Clocks
}

\author{
C. SAini ${ }^{1}$, D.M. Suter ${ }^{1,2}$, A. Liani ${ }^{1}$, P. Gos $^{1}$, And U. Schibler ${ }^{1}$ \\ ${ }^{1}$ Department of Molecular Biology and National CCR Frontiers in Genetics, Sciences III, \\ University of Geneva, 1211 Geneva-4, Switzerland \\ Correspondence: ueli.schibler@unige.ch
}

\begin{abstract}
Mammalian physiology has to adapt to daily alternating periods during which animals either forage and feed or sleep and fast. The adaptation of physiology to these oscillations is controlled by a circadian timekeeping system, in which a master pacemaker in the suprachiasmatic nucleus (SCN) synchronizes slave clocks in peripheral organs. Because the temporal coordination of metabolism is a major purpose of clocks in many tissues, it is important that metabolic and circadian cycles are tightly coordinated. Recent studies have revealed a multitude of signaling components that possibly link metabolism to circadian gene expression. Owing to this redundancy, the implication of any single signaling pathway in the synchronization of peripheral oscillators cannot be assessed by determining the steady-state phase, but instead requires the monitoring of phase-shifting kinetics at a high temporal resolution.
\end{abstract}

In mammals, most physiological processes undergo daily oscillations that are controlled by an endogenous circadian timing system and/or daytime-dependent environmental changes (Fig. 1) (Dibner et al. 2010). The term "circadian" comes from the Latin words "circa diem" (around a day) and indicates that circadian time is similar but not identical to geophysical time. For example, the clocks of mice and humans free-run with period lengths of slightly under and over $24 \mathrm{~h}$, respectively. Hence, their oscillators must be readjusted every day by a few minutes to stay in resonance with geophysical time. This is achieved primarily by daily variations in light intensities that are perceived by the retina and conveyed via the retino-hypothalamic tract to neurons of suprachiasmatic nuclei. The suprachiasmatic nucleus (SCN), composed of two small groups of neurons located in the ventral hypothalamus right above the optical chiasma, has been identified as the central circadian pacemaker by elegant lesion and transplantation experiments (Ralph et al. 1990; Silver et al. 1996). Meanwhile, self-sustained and cell-autonomous circadian oscillators have been discovered in cultured cells (Balsalobre et al. 1998) and in explants of several peripheral tissues (Yamazaki et al. 2000; Yoo et al. 2004). The molecular makeup of cellular clocks is virtually identical in SCN neurons and peripheral cell types. In both of them, the circadian rhythm generation is thought to be based on interlocked negative feedback loops in gene expression (Ko and Takahashi 2006; Dibner et al. 2010). The major loop consists of two period genes, Per1 and Per2, and two cryptochrome genes, Cryl and Cry2. These genes are activated by heterodimers of the PAS domain helix-loop-helix transcription factors BMAL1 and CLOCK (and its closely related paralog NPAS2 in the brain). PER and CRY proteins form heteropolymeric complexes with additional proteins, such as the casein kinases $1 \varepsilon(\mathrm{CK} 1 \varepsilon)$ and $1 \delta$ (CK1 $\delta$ ), the nucleic-acid-binding proteins NONO and PSF, the SIN3-HDAC complex, and the histone methyltransferase adaptor protein WDR5 (Brown et al. 2005; Duong et al. 2011). Once these protein complexes have reached a critical activity, they inhibit Per and Cry gene expression by attenuating the activity of BMAL1CLOCK/NPAS2 heterodimers. As a consequence, the levels of PER and CRY messenger RNA (mRNA) and proteins decrease, and a new cycle of CRY and PER expression can ensue. This feedback circuitry also affects the expression of BMAL1 and, to a lesser extent, that of CLOCK, through an accessory loop involving transcriptional activators of the retinoic acid-related orphan receptors (ROR $\alpha, \operatorname{ROR} \beta$, and ROR $\gamma)$ and repressors of the REV-ERB orphan receptor family (REV-ERB $\alpha$ and REV-ERB $\beta$ ). Both RORs and REV-ERBs bind to two ROR-binding elements (ROREs) within the Bmall promoter (Preitner et al. 2002) and the first Clock intron (Crumbley and Burris 2011), respectively, but whereas RORs activate transcription, REV-ERBs recruit the NCOR1-HDAC3 corepressor complex and thereby reduce transcription (Feng et al. 2011). In addition to transcriptional mechanisms, posttranslational modifications of core clock proteins also play crucial roles in the circadian clockwork circuitry (Vanselow and Kramer 2007; Virshup et al. 2007; Reischl and Kramer 2011). Thus, phosphorylation of PER proteins by CK1 and other kinases tune the period length of the oscillations by affecting PER protein stability and activity. Moreover, CLOCK, BMAL1, CRYs, and REV-ERB $\alpha$ are all phosphoproteins, although many of the relevant kinases remain to be identified. Other posttranslational modifications have also been found on core clock proteins. Thus, CLOCK can be sumoylated (Cardone et al. 2005)

\footnotetext{
${ }^{2}$ Present address: Department of Chemistry and Chemical Biology, Harvard University, Cambridge, MA 02138. Copyright (C) 2011 Cold Spring Harbor Laboratory Press; all rights reserved; doi: 10.1101/sqb.2011.76.010918 Cold Spring Harbor Symposia on Quantitative Biology, Volume LXXVI
} 


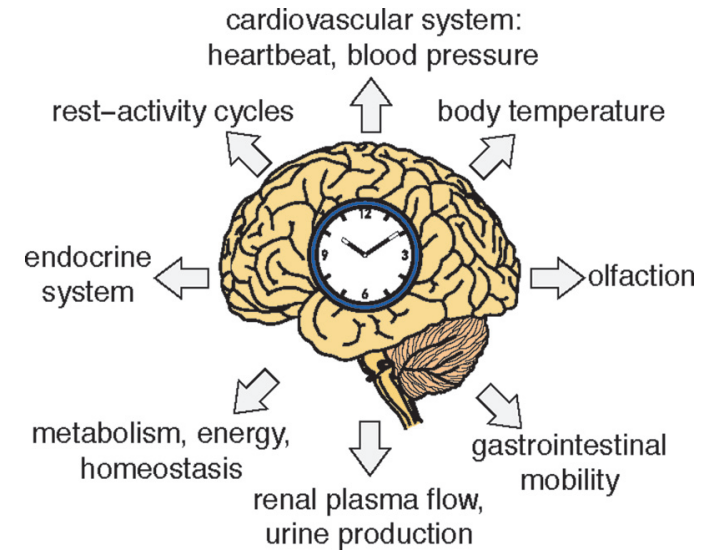

Figure 1. Mammalian physiology undergoes daily oscillations. The master clock in the brain's suprachiasmatic nuclei (in conjunction with daily oscillations in environmental factors) controls rest-activity cycles, circadian fluctuations of the cardiovascular system (heart beat frequency, blood pressure), body temperature, the endocrine system, renal activity, intestinal motility (Hoogerwerf 2010), and metabolism in organs such as liver, endocrine pancreas, adipose tissue, and muscle, as well as sensorial acuity (e.g., olfaction) (Granados-Fuentes et al. 2006). The metabolism of xenobiotics (e.g., toxins ingested with food, medical drugs) in liver, kidney, and small intestine is also highly circadian.

and poly(ADP)-ribosylated (Asher et al. 2010). PER2 and BMAL1 can be acetylated (by CLOCK [Doi et al. 2006; Grimaldi et al. 2009] and, probably, additional acetyltransferases) and deacetylated in a circadian fashion by the $\mathrm{NAD}^{+}$-dependent deacetylase Sirtuin 1 (SIRT1) (Asher et al. 2008; Nakahata et al. 2008). Moreover, the degradation of PER (Reischl et al. 2007) and CRY (Busino et al. 2007; Godinho et al. 2007; Siepka et al. 2007) proteins is regulated by specific ubiquitin ligase complexes.

Whereas the molecular clockwork circuitries are virtually identical in SCN neurons and peripheral cell types, two important differences subsist. The first concerns a redundancy in the positive limb of SCN oscillators that is not relevant in peripheral cell types. Thus, in Clock knockout mice, the close CLOCK paralog NPAS2 can substitute for the function of CLOCK in driving circadian locomotor activity in constant darkness (DeBruyne et al. 2007a). In contrast, CLOCK is indispensable for circadian oscillator function in peripheral cell types (DeBruyne et al. 2007b). The second and probably more important difference between the SCN and peripheral organs concerns the communication of phase information between individual cells. In the SCN, the cellular oscillators are coupled through neuronal and paracrine signals, and this establishes phase coherence in the SCN (Welsh et al. 2010). Even in cultured brain sections, SCN neurons maintain the same phase for days to weeks. Moreover, the coupling of oscillators renders them more resilient to noise and mutations in individual clock genes. For example, whereas high-amplitude oscillations in gene expression persist in organotypic SCN cultures of Cryl knockout mice, dissociated (i.e., uncoupled) individual cultured neurons from such SCNs do not display circadian gene expression. The phase coherence and resilience of SCN clocks to noise explain why animals remain rhythmic for extended time periods under conditions under which they do not receive external timing cues. In contrast to the observations made with SCN explants, slices from tissues or fibroblast cultures progressively lose phase coherence during the time span of a few days (Balsalobre et al. 1998; Yamazaki et al. 2000). Likewise, circadian gene expression is dysregulated in peripheral organs of SCN-lesioned mice or hamsters (Yoo et al. 2004; Guo et al. 2006), although it is still controversial whether phase coherence is lost only between organs or even between individual cells of a given tissue. Nonetheless, the SCN appears to be required for coordinated gene expression in peripheral organs, and it is thus thought that this master pacemaker must synchronize peripheral slave oscillators in a daily fashion. In the following sections, we describe the properties of peripheral clocks and their synchronization by systemic cues that are controlled by the SCN and/or fluctuating environmental factors.

\section{PROPERTIES OF PERIPHERAL OSCILLATORS}

The first mammalian clock genes were identified in the late 1990s (King et al. 1997; Shearman et al. 1997; Shigeyoshi et al. 1997; Sun et al. 1997; Gekakis et al. 1998), and they were found to be expressed not only in the SCN but also in many peripheral tissues. These observations did not, however, provide compelling evidence for the presence of clocks in peripheral cell types, because their cyclic expression could have been the result of rhythmic systemic signals controlled by environmental cues and/or by the SCN. Balsalobre and coworkers (1998) then succeeded in demonstrating circadian gene expression in serum-shocked cultured Rat-1 fibroblasts, and similar oscillations were observed 2 years later in tissue explants (Yamazaki et al. 2000). The amplitude of these expression cycles decreased over time, and it was thus not clear whether the cellular oscillators were self-sustained or damping. Single-cell recordings of cells expressing a short-lived fluorescent protein (Fig. 2A) or firefly luciferase from circadian regulatory elements then unambiguously demonstrated that fibroblast clocks are cell autonomous and self-sustained (Nagoshi et al. 2004; Welsh et al. 2004). In fact, they even keep ticking during cell division, and during cytokinesis the mother cell passes its phase on to the two daughter cells (Nagoshi et al. 2004). Perhaps even more surprisingly, the fibroblast clocks are resilient to large fluctuations in general transcription rates (Dibner et al. 2009). Following treatment of cells with sublethal doses of the antibotics actinomycin D and $\alpha$-amanitin, which reduced global RNA polymerase II transcription rates by threefold, the oscillators remained operative and even ticked at a higher pace. Obviously, these observations are not readily compatible with the simplest version of a transcriptional/translational feedback loop model. Therefore, it must be the activity rather than the accumulation of core clock components 
A
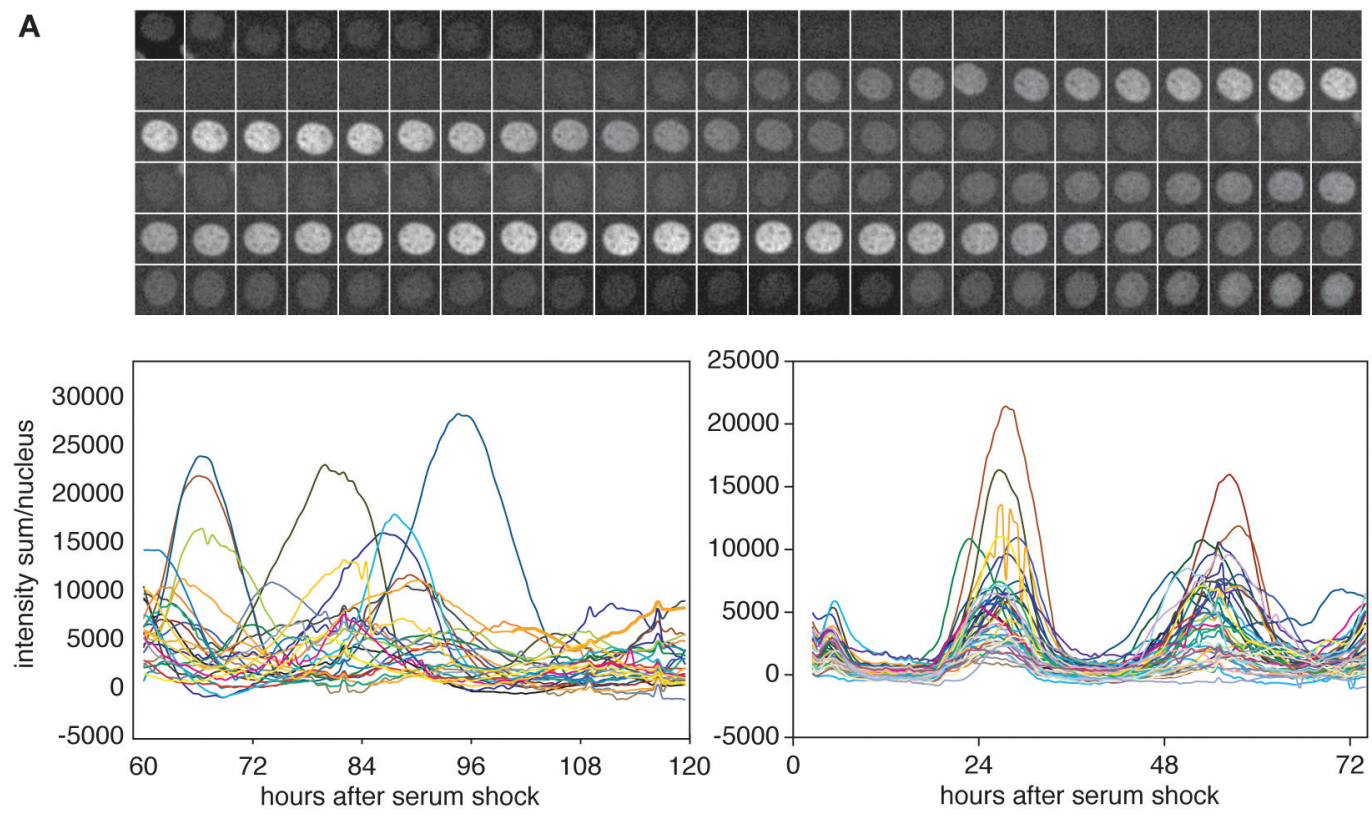

B
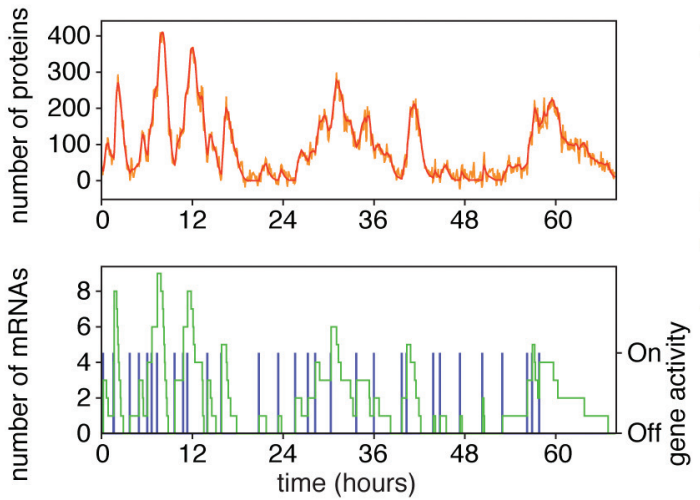

C

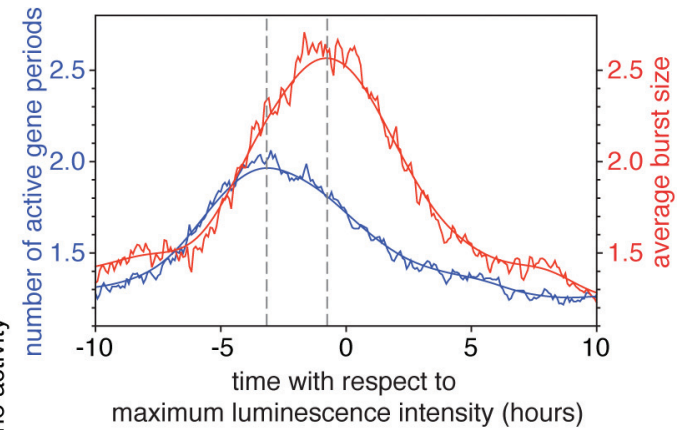

Figure 2. Properties of circadian oscillators studied in cultured cells. Gene expression can be recorded in real time in individual living cells by fluorescence or luminescence time-lapse microscopy of cell lines that harbor transgenes specifying fluorescent proteins or luciferase, respectively. (A) Time-lapse microscopy of cells expressing a yellow fluorescent protein from Rev-erb $\alpha$ regulatory sequences (see Nagoshi et al. 2004). (Top panel) A picture was taken every 30 min during 3 consecutive days. Tracings of time series for multiple cells in unsynchronized cells (lower left panel; the first image was taken $60 \mathrm{~h}$ after the medium change) and synchronized cells (lower right panel; time lapse microscopy was initiated immediately after a serum shock). $(B)$ Bioluminescence tracing of a cell expressing a single Bmall-luciferase reporter gene specifying a short-lived mRNA encoding a nuclear luciferase with a half-life of only $22 \mathrm{~min}$. The tracing was obtained by recording the cell using an Olympus LV200 luminoview microscope equipped with an electron multiplying charge coupled device (EM-CCD) cooled camera at a temporal resolution of 5 min for 72 h (i.e., photons were accumulated during a 5-min period). The bioluminescence tracing was used to calculate the transcriptional bursting pattern (see text). $(C)$ Traces (such as those shown in $B$ ) from multiple cells were used to calculate mean frequencies and sizes of transcriptional bursts, and the resulting profiles were centered around the maximal luminescence emission. (Data presented in $A$ from Nagoshi et al. 2004, with permission, from Elsevier; $B$ and $C$ data from Suter et al. 2011.)

that is critical for circadian oscillator function, and the temporal coordination of posttranslational clock protein modifications probably plays a predominant role in the rhythm-generating feedback loops.

The analysis of circadian gene expression in individual cells has been very informative with regard to the nature of cell-autonomous oscillators. Because most single-cell recordings were performed at a relatively low temporal resolution, they did not reveal the fine kinetics of circadian transcription. Most genes (including those expressed in a circadian fashion) are actually transcribed at relatively low levels and in a highly discontinuous manner. For example, Tata box-binding protein mRNA accumulates to about six copies per liver cell. The stability of this mRNA has not been determined in liver, but even if we assumed a short half-life of $2 \mathrm{~h}$, each of the two Tbp genes would have to produce only about one transcript per hour. The discontinuity of transcription can be described by the random telegraph model, according to which a gene is either on or off (Golding et al. 2005; 
Raj et al. 2006; Pedraza and Paulsson 2008; Larson et al. 2009). During the on states, also known as transcriptional bursts, the number of mRNA molecules produced is called the "burst size." In the case of the Tbp gene mentioned above, the off times would be several hours if the average burst size was $>1$. We have recently established an experimental system allowing the recording of transcription kinetics for single genes in real time and in living cells (Suter et al. 2011). Briefly, resident genes or transgenes are tagged with a cassette expressing a shortlived mRNA (half-life $\sim 60 \mathrm{~min}$ ) encoding a destabilized nuclear luciferase (half-life $\sim 22 \mathrm{~min}$ ). Using ultrasensitive bioluminescence microscopy, the nuclear luminescence was then recorded at high temporal resolution (one frame $/ 5 \mathrm{~min}$ ) in individual cells containing a single luciferase cassette. Using mathematical deconvolution, the burst frequencies and sizes could be computed from the high-resolution bioluminescence traces of single cells. When applied to cells expressing a Bmal1-luciferase transgene in a circadian fashion (Fig. 2B), this technology revealed that the phase of burst frequency is advanced with regard to that of burst size (Fig. 2C). The Bmal1-luciferase gene displays about 10 bursts per day, and together these active episodes last $\sim 2 \mathrm{~h}$. Thus, the Bmal1-luciferase transgene is active for only about $8 \%-9 \%$ of the time. Likewise, endogenous genes expressed throughout the day have been found to be active for only between $3 \%$ and $15 \%$ of the time. When monitored in multiple cells over multiple days, the average burst frequencies, burst sizes, and fractions of time during which the genes were active provided precise signatures (bar codes) for both constitutively and circadianly expressed genes. However, at any given time, expression levels varied dramatically between individual cells. This technology was also applied to primary fibroblasts from PER2::luc mice, which produce a PER2-luciferase protein from the endogenous Per 2 locus and in which the fusion proteins successfully substitute for the function of PER2. Because even cells expressing low levels of PER2::luc are perfectly rhythmic, the absolute level of this core clock protein appears to be less important than its activity.

\section{MANY SIGNALING PATHWAYS CAN SYNCHRONIZE CLOCKS IN PERIPHERAL CELLS}

Soon after the discovery of clocks in cultured cells, we and other investigators observed that these oscillators can be synchronized by a puzzling variety of substances including glucocorticoid hormones, retinoic acids, fibroblast growth factor (FGF), endothelin, prostaglandins, forskolin, tumor promoters, $\mathrm{Ca}^{2+}$ ionophors, glucose, and synthetic ligands of the orphan receptor REV-ERB $\alpha$ (Gachon et al. 2004; Meng et al. 2008). As plasma contains many hormones, growth factors, and cytokines, it is perhaps not surprising that it efficiently resets the phases of circadian oscillators in cultured cells (Balsalobre et al. 1998). The interaction of membrane receptors with their cognate ligands usually results in the activation of protein kinases, which then phosphorylate and activate downstream regulators, such as immediate early transcription factors (IETF). In vitro studies indicated that cAMP response element binding (CREB) plays an important role as an IETF in the synchronization of peripheral clocks (Gachon et al. 2004). cAMP signaling also contributes to core clock function in SCN neurons and peripheral cell types (O'Neill et al. 2008), and the temporal regulation of $\mathrm{CREB}$ activity is thus an attractive candidate mechanism for the phase entrainment of both central and subsidiary clocks. Intriguingly, the clocks of cultured cells can also be phase-entrained by simulated body temperature oscillations with less than 1.1-fold amplitudes (Brown et al. 2002; Buhr et al. 2010; C Saini, J Morf, P Gos, et al., in prep.). Finally, DNA damage caused by ionizing radiation can act as a phase-shifting cue in cultured cells and animals (Oklejewicz et al. 2008).

We wish to emphasize that the results obtained with cultured fibroblasts cannot decide whether the pathways listed above are also relevant in the synchronization of peripheral timekeepers in vivo, and the analysis of molecular mechanisms involved in the phase resetting of clocks in peripheral organs is still in its early infancy. Daily feeding-fasting cycles are clearly the most dominant zeitgebers for clocks in liver and several other organs (Damiola et al. 2000; Stokkan et al. 2001), underscoring the importance of peripheral circadian clocks in the temporal orchestration of metabolism (Fig. 3). However, the molecular signals conveying metabolic states to circadian oscillator components are still mysterious. Conceivably, these include hormones secreted upon feeding or fasting, such as cholecystokinin, peptide YY, oxyntomodulin, ghrelin, leptin (Konturek et al. 2004), bloodborne food metabolites, and intracellular metabolites reflecting redox state, such as the reduced and oxidized forms of the nicotinamide adenine dinucleotides NAD and NADP. Very recently, two reports demonstrated that the $\mathrm{NAD}^{+} / \mathrm{NADH}$ ratio is indeed subject to circadian fluctuations, in part owing to the rhythmic expression of nicotinamide phosphoribosyltransferase (Nakahata et al. 2009; Ramsey et al. 2009). Biochemical experiments by McKnight and coworkers suggest that the NAD $(\mathrm{P}) \mathrm{H} /$ $\mathrm{NAD}(\mathrm{P})^{+}$ratio affects the binding of CLOCK/NPAS2BMAL1 heterodimers to their cognate DNA sequences (Rutter et al. 2001). The NAD ${ }^{+}$-dependent histone deacetylase SIRT1 may be another candidate for connecting cellular metabolism to circadian gene expression (Asher et al. 2008; Nakahata et al. 2008). SIRT1 not only deacetylates amino-terminal histone tails but also various transcription factors and coactivators (Zschoernig and Mahlknecht 2008). Genetic and biochemical experiments suggested that SIRT1 indeed influences the circadian expression of several clock genes (Asher et al. 2008; Nakahata et al. 2008). Another $\mathrm{NAD}^{+}$-dependent enzyme, poly(ADP-ribose) polymerase 1 (PARP-1), has recently been implicated in the phase resetting of liver clocks. PARP-1 adds poly(ADP-ribose) residues to itself and to CLOCK in a diurnal manner, and whereas PARP-1 has little effect on circadian gene expression in animals kept under normal conditions, it does affect the kinetics 


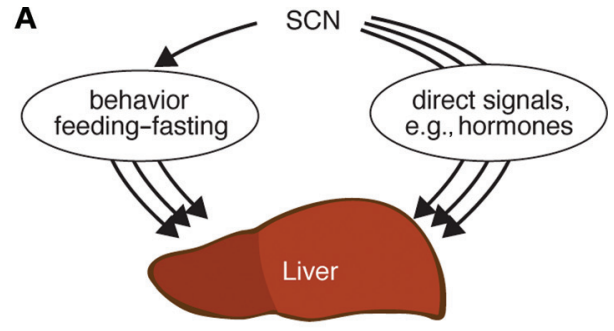

B

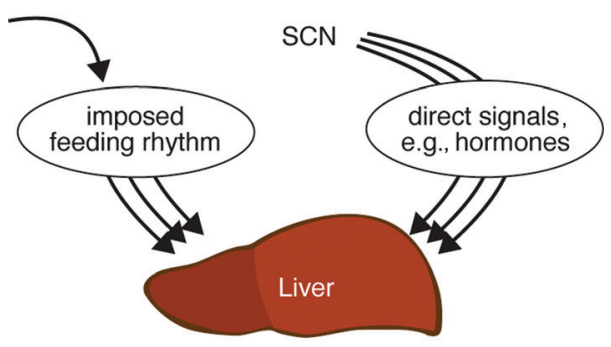

C

all signaling pathways functional

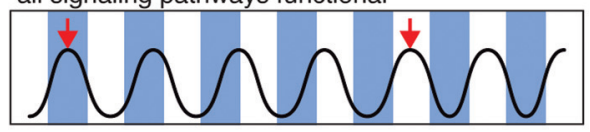

SCN-dependent pathway disrupted

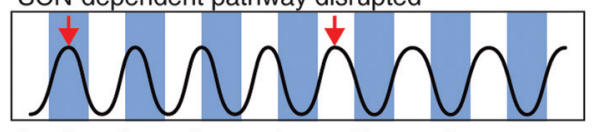

feeding-dependent pathway disrupted

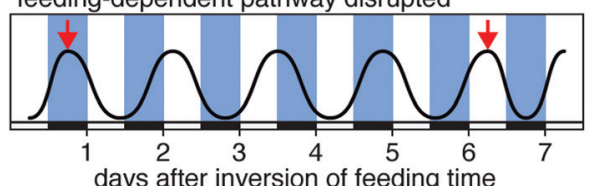

Figure 3. Synchronization of liver clocks by feeding cycles and more direct SCN timing cues. $(A)$ Under normal conditions, the SCN synchronizes the clock in liver and several other peripheral organs indirectly by imposing feeding cycles and more directly by humoral cues and body temperature rhythms. $(B)$ When feeding rhythms are inverted, the hepatocyte clocks gradually adapt their phase to that of the feeding rhythms. Feeding- or fastingdependent zeitgebers are now in conflict with the more direct cues controlled by the SCN. (C) When signaling pathways directly depending on the SCN, such as glucocorticoid secretion, are disrupted, the kinetics of synchronization by feeding cycles is accelerated. Conversely, the kinetics is slowed down when feeding-dependent pathways (e.g., those involving poly[ADPribose] polymerase 1) are impaired. (Figure adapted from Asher and Schibler 2011, with permission, from Elsevier.)

of phase adaptation to feeding rhythms (Asher et al. 2010).

Plasma levels of glucocorticoid hormones display robust daily oscillations in laboratory rodents and humans, reaching peak levels toward the end of the rest phase (i.e., during the evening and morning in nocturnal rodents and diurnal humans, respectively) (Lightman 2008). Glucocorticoid hormones stimulate gluconeogenesis at the time that glycogen is depleted during the fasting period. However, the phase of their daily oscillation in the bloodstream is not readily inverted by altered feeding-fasting rhythms (Le Minh et al. 2001). Hence, the regulation of their circadian production and secretion appears to be dominated by the SCN, which does not adapt its phase to inverted feeding rhythms. Similar to the observations made with PARP-1 knockout mice (Asher et al. 2010), the disruption of the glucocorticoid receptor (GR) in hepatocytes affects the kinetics of phase shifting induced by the inversion of the feeding cycle. However, in stark contrast to PARP-1 loss of function, the depletion of GR accelerates the food-induced phase resetting (Fig. 3B,C) (Le Minh et al. 2001).

\section{HOW TO DEAL WITH REDUNDANCY}

Given the multitude of signaling mechanisms involved in the phase entrainment of peripheral clocks, the phase is not dramatically influenced by the elimination of an individual pathway. Hence, measuring the steady-state phase in the absence or presence of a given signaling component cannot provide reliable information as to whether the component under investigation fulfills a role in the synchronization of these timekeepers. However, as pointed out for GR and PARP-1 in the previous section, the velocity of phase shifting after an inversion of the feeding regimen is much more sensitive to the absence or presence of an individual signaling pathway. Moreover, the effects of different pathways on the kinetics of phase shifting induced by feeding-fasting can be exploited to discriminate between zeitgeber signals that are controlled by either the SCN or feeding-fasting cues (Fig. 3). If the phase of the feeding-fasting cycles in conflict with that imposed by the SCN, the synchronization game resembles a tug-of-war between metabolic cues and signals emanating from the SCN. The former will always dominate the latter, but the time necessary to win depends on the number of players involved. If a feeding-fasting player is eliminated, the synchronization to metabolic signals will take longer. Conversely, the removal of an SCN player will accelerate this process. Using conventional methods, the experiments required for the recording of phase-shifting kinetics (e.g., in mouse liver) involve the preparation of RNA or protein samples from two different genotypes at frequent intervals during multiple days and thus require a large number of animals (Asher et al. 2010). Clearly, such brute force approaches do not have a bright future: They are excessively labor-intensive, raise ethical issues with regard to the number of animals needed, provide poor temporal resolution, and, truth be told, discourage pre- and postdoctoral students from joining one's laboratory. We have thus made considerable efforts toward the establishment of a whole-body imaging technique that allows the recording of liver gene expression in real time in freely moving animals at a high temporal resolution. Using adenoviral-vector-mediated transduction of circadian luciferase reporter genes into the liver in combination with micro-osmotic pumps delivering luciferin at constant rates, we can now record circadian gene expression during extended time periods. In these experiments, the bioluminescence cycles emanating from the liver are monitored by photomultiplier 
tubes in freely moving mice at a resolution of 1 min during $>10 \mathrm{~d}$. By using this novel tool, we have already demonstrated that, in SCN-lesioned mice, the feeding-induced phase inversion of circadian liver gene expression is much faster than in intact animals. Using the same technology, we have also shown that, in SCN-lesioned mice, circadian liver gene expression persists for several days in constant darkness before it flattens out (C Saini, P Gos, A Liani, et al., unpubl.). Undoubtedly, this approach will provide invaluable services in the dissection of individual molecular signaling pathways participating in the phase resetting of oscillators in peripheral tissues.

\section{BODY TEMPERATURE RHYTHMS: AN UNEXPECTED ZEITGEBER}

How do systemic cues controlled by environmental factors and/or the SCN phase-entrain oscillators in peripheral tissues? Most signaling cascades eventually result in the conversion of an inactive to an active IETF. For diurnally oscillating signals, the activity of such IETFs is supposed to be rhythmic, as would be expected of the expression of the IETF target genes (i.e., immediate early genes). If the immediate early genes comprise a core clock gene, this would readily explain how the phase of systemic signals could be conveyed to the circadian oscillator circuitry. We thus wished to discriminate between systemically driven genes and genes whose cyclic expression is regulated by the local oscillators, because some of the former may serve in clock input pathways. To this end, we engineered a mouse strain in which hepatocyte oscillators can be switched on and off at will by including or omitting doxycycline, respectively, in food or drinking water (Kornmann et al. 2007a,b). By using genome-wide transcriptome profiling of liver RNA harvested during $2 \mathrm{~d}$ at 4-h intervals around the clock, we identified approximately 50 genes (out of a total of about 350 cyclic transcripts) that maintained circadian expression in the absence of functional hepatocyte clocks. At least some of these systemically driven genes may function as immediate early genes in the synchronization of hepatic oscillators. Intriguingly, Per 2 was one of these genes, and Per2 transcription can thus be controlled by both systemic cues and local oscillators. PER2 is therefore expected to play a prime function in conveying SCNdriven systemic signals to hepatocyte oscillators. Other interesting genes that emerged from this screen, and that are possibly involved in the phase entrainment of hepatocytes, appear to be related to body temperature oscillations. These include several heat shock proteins (HSPs) and the cold-inducible RNA-binding proteins (e.g., CIRP and FUS/TLS). The mRNAs encoding HSPs reach zenith levels when body temperature is maximal, whereas the mRNAs specifying cold-inducible RNA-binding proteins reach zenith levels when body temperature is minimal. Whereas the regulation of coldinducible genes is poorly understood, heat shock factor 1 (HSF1) has been identified as the major temperaturesensitive regulator of $H s p$ transcription (for review, see Anckar and Sistonen 2011). Intriguingly, we identified
HSF1 as a diurnally regulated transcription factor by a completely independent approach designed in our laboratory, dubbed differential display of DNA-binding proteins (DDDP) (Reinke et al. 2008). The motivation for developing this strategy was based on the fact that the activity of early transcription factors is not accompanied by changes in mRNA levels and that these would thus have escaped the circadian transcriptome profiling approach outlined above. The principle underlying DDDP is the observation that transcription-factor-binding sites, usually encompassing $\sim 8-12 \mathrm{bp}$, are quite promiscuous and allow for several mismatches with regard to the optimal consensus sequence. For example, even a transcription-factor-binding site composed of $12 \mathrm{bp}$ is expected to exist approximately once every $14,000 \mathrm{bp}$ in synthetic random DNA, if two mismatches were permitted. The statistical frequency of less complex binding sites is obviously even higher. We took advantage of this degeneracy and screened a synthetic random DNA library encompassing 40,000 bp (subdivided in 100-mers) of synthetic DNA by electrophoretic mobility shift assays with liver nuclear proteins harvested at 4-h intervals around the clock. Several hits were obtained for most known transcription factors with circadian accumulation or DNAbinding activity (e.g., PAR bZip proteins, REV-ERB $\alpha$, CLOCK-BMAL1). As mentioned above, the DDDP screen also revealed HSF-1 as a transcription factor whose nuclear translocation and DNA binding oscillated with high daily amplitude in the liver. Chromatin immunoprecipitation experiments confirmed that HSF1 occupies its target sequences in Hsp genes in a highly diurnal fashion, suggesting that the rhythmic expression of Hsp is caused by the cyclic activity of HSF1.

Previous work has shown that the phase of circadian oscillators in cultured fibroblasts can be entrained by square waves of temperature (Brown et al. 2002). Although the phase of already synchronized oscillators could be maintained for additional days in fibroblasts exposed to simulated mouse body temperature rhythms, it could not be established de novo by such smooth, lowamplitude temperature cycles. However, when such experiments were conducted for longer time periods with NIH3T3 fibroblasts stably expressing circadian luciferase reporter genes, it turned out that simulated mouse body temperature cycles oscillating between $35^{\circ} \mathrm{C}$ and $38^{\circ} \mathrm{C}$ could eventually synchronize circadian gene expression in a high fraction of cells. Surprisingly, even simulated human temperature rhythms oscillating by only $1{ }^{\circ} \mathrm{C}$ could still synchronize about $20 \%$ of the cells. Loss-of-function experiments (C Saini, J Morf, P Gos, et al., in prep.) and experiments with a pharmacological inhibitor of HSF activity (Buhr et al. 2010) demonstrated that HSF1 is clearly participating in the temperaturedependent synchronization of peripheral clocks. Nonetheless, even HSF1-deficient cells can eventually adapt to simulated body temperature rhythms, and HSF1 can thus not be the only regulator in this process. Hsfl has three paralogs, $H_{s f 2}, H_{s f 3}$, and $H_{s f 4}$, in the mouse genome (Pirkkala et al. 2001; Fujimoto and Nakai 2010), but based on deep RNA sequencing, only $H_{s} f 2$ is 
expressed in addition to $H s f l$ at significant levels in NIH3T3 fibroblasts. Moreover, the depletion of HSF2 via RNA interference had no effect on the temperaturedependent synchronization of the clocks operative in these cells. Hence, we believe that temperature sensors other than HSFs, for example, thermosensitive transient receptor potential channels (thermoTRPs) (Vay et al. 2011), may participate in this process.

\section{CONCLUDING REMARKS}

Thus far, most experiments addressing mechanisms by which the SCN synchronizes peripheral circadian clocks have been conducted with liver and cultured fibroblasts. As suggested by genome-wide transcription profiling experiments (Hughes et al. 2009 and references therein) and proteomics studies (Reddy et al. 2006), the temporal orchestration of metabolism is probably the major purpose of circadian gene expression in the liver and other metabolic organs, such as adipose tissues (Gimble et al. 2011) and muscle (Lefta et al. 2011). We wish to emphasize that circadian clocks do not work in isolation, but in tight cooperation with acute regulatory mechanisms. For example, glucose homeostasis is governed by circadian oscillators in pancreatic $\beta$ cells (Marcheva et al. 2010) and hepatocytes (Lamia et al. 2008), hormones of the endocrine pancreas such as insulin and glucagon, glucose-sensitive neurons in the brain stem and the hypothalamus acting through the peripheral nervous system on the endocrine pancreas (Marty et al. 2007), glucocorticoid hormones, and allosteric mechanisms depending on metabolite concentration that tunes the activity of the enzymes responsible for glucose storage, catabolism, and anabolism (Asher and Schibler 2011). Likewise, xenobiotic detoxification is tuned by a combination of diurnal regulation of gene expression and substrate-induced responses acting through transcription factors such as constitutive androstane receptor (CAR), pregnane $\mathrm{X}$ receptor, peroxisome proliferator-activated receptor $\alpha$, and arylcarbohydrate/dioxin receptor (for review, see Levi and Schibler 2007). These regulators induce the transcription of genes specifying a number of cytochrome p450 mono-oxidases, cytochrome p450 oxidoreductase, conjugating enzymes (e.g., sulfatases and esterases), and ATP transporters, which help to eliminate toxic xenobiotics (and endobiotics) by rendering them more watersoluble and excreting them. Many of the regulators and enzymes belonging to this detoxification system are expressed in a circadian manner, but they are induced in addition by the xenobiotics in whose metabolism they are involved. For example, in liver and small intestine of mice, phenobarbital activates the expression of Cyp2B10, one of its metabolizing cytochrome 450 enzymes, much more efficiently during the night than during the day. Presumably, this reflects the circadian expression of CAR, whose expression is circadian and whose activity is phenobarbital inducible (Gachon et al. 2006). Because many medical drugs are metabolized by the xenobiotic detoxification system, one of the major future challenges will be to explore the circadian activity of this system in the clinic (Levi and Schibler 2007). Unfortunately, only few clinical groups are currently trying to incorporate daily oscillating physiology (such as circadian pharmacokinetics) into the design of therapy regimens (Innominato et al. 2010).

Metabolic and circadian cycles are so intricately interwoven that attempts to separate them are bound to be somewhat arbitrary (Chen and McKnight 2007; Reddy and O'Neill 2011). According to recently published findings on the redox state of peroxiredoxins, metabolic clocks may actually be the centerpiece of circadian oscillators. Peroxiredoxins are highly conserved in a wide variety of organisms harboring circadian clocks, including cyanobacteria, algae, plants, and humans. Moreover, daily alternations between oxidized and reduced forms of peroxiredoxins have been observed in the pico-eukaryotic alga Ostreococcus tauri (O'Neill et al. 2011) and human red blood cells (O'Neill and Reddy 2011). Hence, this 24-h redox cycle-which runs in the absence of transcription and translation-has been phylogenetically conserved for more than a billion years. Irrespective of whether the peroxiredoxin redox rhythms are part of a yet to be discovered metabolic oscillator or an output of it, these observations open the exciting possibility that the circadian clockwork circuitry of all organisms is based on the same molecular principles. If true, this would come as a great relief to those of us who follow Jacques Monod's credo, "Anything found to be true of E. coli must also be true of elephants." Indeed, the lack of structural similarity among clock components of cyanobacteria, fungi, plants, and metazoans (Dunlap 1999; Harmer et al. 2001; Rosbash 2009) was disturbing, because the independent evolution of such a complex clockwork circuitry from scratch violates Occam's Razor. Once a central mechanism exists, it is easier to add additional layers around it that are adapted to the needs of a particular organism. The evolution of eyes as different as Planarian ocelli, insect compound eyes, and our highly complex lensed eyes is probably the most beautiful documentation of a monophyletic origin for functionally equivalent but structurally different biological features (Gehring 2011).

\section{ACKNOWLEDGMENTS}

We thank Nicolas Roggli for the artwork. The work performed in our laboratory was supported by the Swiss National Foundation (grants SNF 31-113565 and SNF 31-128656/1 and the National Center of Confidence in Research program grant Frontiers in Genetics), the European Research Council (ERC-2009-AdG 20090506), the State of Geneva, and the Louis Jeantet Foundation of Medicine.

\section{REFERENCES}

Anckar J, Sistonen L. 2011. Regulation of HSF1 function in the heat stress response: Implications in aging and disease. Annu Rev Biochem 80: 1089-1115.

Asher G, Schibler U. 2011. Crosstalk between components of circadian and metabolic cycles in mammals. Cell Metab 13: $125-137$. 
Asher G, Gatfield D, Stratmann M, Reinke H, Dibner C, Kreppel F, Mostoslavsky R, Alt FW, Schibler U. 2008. SIRT1 regulates circadian clock gene expression through PER2 deacetylation. Cell 134: 317-328.

Asher G, Reinke H, Altmeyer M, Gutierrez-Arcelus M, Hottiger MO, Schibler U. 2010. Poly(ADP-Ribose) polymerase 1 participates in the phase entrainment of circadian clocks to feeding. Cell 142: 943-953.

Balsalobre A, Damiola F, Schibler U. 1998. A serum shock induces circadian gene expression in mammalian tissue culture cells. Cell 93: 929-937.

Brown SA, Zumbrunn G, Fleury-Olela F, Preitner N, Schibler U. 2002. Rhythms of mammalian body temperature can sustain peripheral circadian clocks. Curr Biol 12: 1574-1583.

Brown SA, Ripperger J, Kadener S, Fleury-Olela F, Vilbois F, Rosbash M, Schibler U. 2005. PERIOD1-associated proteins modulate the negative limb of the mammalian circadian oscillator. Science 308: 693-696.

Buhr ED, Yoo SH, Takahashi JS. 2010. Temperature as a universal resetting cue for mammalian circadian oscillators. Science 330: 379-385.

Busino L, Bassermann F, Maiolica A, Lee C, Nolan PM, Godinho SI, Draetta GF, Pagano M. 2007. SCFFbxl3 controls the oscillation of the circadian clock by directing the degradation of cryptochrome proteins. Science 316: 900-904.

Cardone L, Hirayama J, Giordano F, Tamaru T, Palvimo JJ, Sassone-Corsi P. 2005. Circadian clock control by SUMOylation of BMAL1. Science 309: 1390-1394.

Chen Z, McKnight SL. 2007. A conserved DNA damage response pathway responsible for coupling the cell division cycle to the circadian and metabolic cycles. Cell Cycle 6: 2906-2912.

Crumbley C, Burris TP. 2011. Direct regulation of CLOCK expression by REV-ERB. PloS One 6: e17290.

Damiola F, Le Minh N, Preitner N, Kornmann B, Fleury-Olela F, Schibler U. 2000. Restricted feeding uncouples circadian oscillators in peripheral tissues from the central pacemaker in the suprachiasmatic nucleus. Genes Dev 14: 2950-2961.

DeBruyne JP, Weaver DR, Reppert SM. 2007a. CLOCK and NPAS2 have overlapping roles in the suprachiasmatic circadian clock. Nat Neurosci 10: 543-545.

DeBruyne JP, Weaver DR, Reppert SM. 2007b. Peripheral circadian oscillators require CLOCK. Curr Biol 17: R538-R539.

Dibner C, Sage D, Unser M, Bauer C, d'Eysmond T, Naef F, Schibler U. 2009. Circadian gene expression is resilient to large fluctuations in overall transcription rates. $E M B O J \mathbf{2 8}$ : $123-134$.

Dibner C, Schibler U, Albrecht U. 2010. The mammalian circadian timing system: Organization and coordination of central and peripheral clocks. Annu Rev Physiol 72: 517-549.

Doi M, Hirayama J, Sassone-Corsi P. 2006. Circadian regulator CLOCK is a histone acetyltransferase. Cell 125: $497-$ 508.

Dunlap JC. 1999. Molecular bases for circadian clocks. Cell 96: 271-290.

Duong HA, Robles MS, Knutti D, Weitz CJ. 2011. A molecular mechanism for circadian clock negative feedback. Science 332: $1436-1439$.

Feng D, Liu T, Sun Z, Bugge A, Mullican SE, Alenghat T, Liu XS, Lazar MA. 2011. A circadian rhythm orchestrated by histone deacetylase 3 controls hepatic lipid metabolism. Science 331: $1315-1319$.

Fujimoto M, Nakai A. 2010. The heat shock factor family and adaptation to proteotoxic stress. FEBS J 277: 4112-4125.

Gachon F, Nagoshi E, Brown SA, Ripperger J, Schibler U. 2004. The mammalian circadian timing system: From gene expression to physiology. Chromosoma 113: 103-112.

Gachon F, Olela FF, Schaad O, Descombes P, Schibler U. 2006. The circadian PAR-domain basic leucine zipper transcription factors DBP, TEF, and HLF modulate basal and inducible xenobiotic detoxification. Cell Metab 4: 25-36.

Gehring WJ. 2011. Chance and necessity in eye evolution. Genome Biol Evol 3: 1053-1066.
Gekakis N, Staknis D, Nguyen HB, Davis FC, Wilsbacher LD, King DP, Takahashi JS, Weitz CJ. 1998. Role of the CLOCK protein in the mammalian circadian mechanism. Science 280: $1564-1569$.

Gimble JM, Sutton GM, Bunnell BA, Ptitsyn AA, Floyd ZE. 2011. Prospective influences of circadian clocks in adipose tissue and metabolism. Nat Rev 7: 98-107.

Godinho SI, Maywood ES, Shaw L, Tucci V, Barnard AR, Busino L, Pagano M, Kendall R, Quwailid MM, Romero MR, et al. 2007. The after-hours mutant reveals a role for Fbx13 in determining mammalian circadian period. Science 316: $897-900$.

Golding I, Paulsson J, Zawilski SM, Cox EC. 2005. Real-time kinetics of gene activity in individual bacteria. Cell 123: $1025-1036$.

Granados-Fuentes D, Tseng A., Herzog ED. 2006. A circadian clock in the olfactory bulb controls olfactory responsivity. J Neurosci 26: 12219-12225.

Grimaldi B, Nakahata Y, Kaluzova M, Masubuchi S, SassoneCorsi P. 2009. Chromatin remodeling, metabolism and circadian clocks: The interplay of CLOCK and SIRT1. Int J Biochem Cell Biol 41: 81-86.

Guo H, Brewer JM, Lehman MN, Bittman EL. 2006. Suprachiasmatic regulation of circadian rhythms of gene expression in hamster peripheral organs: Effects of transplanting the pacemaker. J Neurosci 26: 6406-6412.

Harmer SL, Panda S, Kay SA. 2001. Molecular bases of circadian rhythms. Annu Rev Cell Dev Biol 17: 215-253.

Hoogerwerf WA. 2010. Role of clock genes in gastrointestinal motility. Am J Physiol 299: G549-G555.

Hughes ME, DiTacchio L, Hayes KR, Vollmers C, Pulivarthy S, Baggs JE, Panda S, Hogenesch JB. 2009. Harmonics of circadian gene transcription in mammals. PLoS Genet 5: e1000442.

Innominato PF, Levi FA, Bjarnason GA. 2010. Chronotherapy and the molecular clock: Clinical implications in oncology. Adv Drug Deliv Revs 62: 979-1001.

King DP, Zhao Y, Sangoram AM, Wilsbacher LD, Tanaka M, Antoch MP, Steeves TD, Vitaterna MH, Kornhauser JM, Lowrey PL, et al. 1997. Positional cloning of the mouse circadian clock gene. Cell 89: 641-653.

Ko CH, Takahashi JS. 2006. Molecular components of the mammalian circadian clock. Hum Mol Genet 15: R271-R277.

Konturek SJ, Konturek JW, Pawlik T, Brzozowski T. 2004. Brain-gut axis and its role in the control of food intake. J Physiol Pharmacol 55: 137-154.

Kornmann B, Schaad O, Bujard H, Takahashi JS, Schibler U. 2007a. System-driven and oscillator-dependent circadian transcription in mice with a conditionally active liver clock. PLoS Biol 5: e 34 .

Kornmann B, Schaad O, Reinke H, Saini C, Schibler U. 2007b. Regulation of circadian gene expression in liver by systemic signals and hepatocyte oscillators. Cold Spring Harb Symp Quant Biol 72: 319-330.

Lamia KA, Storch KF, Weitz CJ. 2008. Physiological significance of a peripheral tissue circadian clock. Proc Natl Acad Sci 105: 15172-15177.

Larson DR, Singer RH, Zenklusen D. 2009. A single molecule view of gene expression. Trends Cell Biol 19: 630-637.

Lefta M, Wolff G, Esser KA. 2011. Circadian rhythms, the molecular clock, and skeletal muscle. Curr Top Dev Biol 96: $231-271$.

Le Minh N, Damiola F, Tronche F, Schutz G, Schibler U. 2001. Glucocorticoid hormones inhibit food-induced phase-shifting of peripheral circadian oscillators. EMBO J 20: 7128-7136.

Levi F, Schibler U. 2007. Circadian rhythms: Mechanisms and therapeutic implications. Annu Rev Pharmacol Toxicol 47: $593-628$.

Lightman SL. 2008. The neuroendocrinology of stress: A never ending story. J Neuroendocrinol 20: $880-884$.

Marcheva B, Ramsey KM, Buhr ED, Kobayashi Y, Su H, Ko CH, Ivanova G, Omura C, Mo S, Vitaterna MH, et al. 2010. Disruption of the clock components CLOCK and BMAL1 leads to hypoinsulinaemia and diabetes. Nature 466: 627-631. 
Marty N, Dallaporta M, Thorens B. 2007. Brain glucose sensing, counterregulation, and energy homeostasis. Physiology 22: 241-251.

Meng QJ, McMaster A, Beesley S, Lu WQ, Gibbs J, Parks D, Collins J, Farrow S, Donn R, Ray D, et al. 2008. Ligand modulation of REV-ERB $\alpha$ function resets the peripheral circadian clock in a phasic manner. J Cell Sci 121: 3629-3635.

Nagoshi E, Saini C, Bauer C, Laroche T, Naef F, Schibler U. 2004. Circadian gene expression in individual fibroblasts: Cell-autonomous and self-sustained oscillators pass time to daughter cells. Cell 119: 693-705.

Nakahata Y, Kaluzova M, Grimaldi B, Sahar S, Hirayama J, Chen D, Guarente LP, Sassone-Corsi P. 2008. The NAD ${ }^{+}$. dependent deacetylase SIRT1 modulates CLOCK-mediated chromatin remodeling and circadian control. Cell 134: 329 340 .

Nakahata Y, Sahar S, Astarita G, Kaluzova M, Sassone-Corsi P. 2009. Circadian control of the $\mathrm{NAD}^{+}$salvage pathway by CLOCK-SIRT1. Science 324: 654-657.

Oklejewicz M, Destici E, Tamanini F, Hut RA, Janssens R, van der Horst GT. 2008. Phase resetting of the mammalian circadian clock by DNA damage. Curr Biol 18: 286-291.

O'Neill JS, Reddy AB. 2011. Circadian clocks in human red blood cells. Nature 469: 498-503.

O’Neill JS, Maywood ES, Chesham JE, Takahashi JS, Hastings MH. 2008. cAMP-dependent signaling as a core component of the mammalian circadian pacemaker. Science 320: 949-953.

O'Neill JS, van Ooijen G, Dixon LE, Troein C, Corellou F, Bouget FY, Reddy AB, Millar AJ. 2011. Circadian rhythms persist without transcription in a eukaryote. Nature 469: 554558.

Pedraza JM, Paulsson J. 2008. Effects of molecular memory and bursting on fluctuations in gene expression. Science 319: 339343.

Pirkkala L, Nykanen P, Sistonen L. 2001. Roles of the heat shock transcription factors in regulation of the heat shock response and beyond. FASEB J 15: 1118-1131.

Preitner N, Damiola F, Lopez-Molina L, Zakany J, Duboule D, Albrecht U, Schibler U. 2002. The orphan nuclear receptor REV-ERB $\alpha$ controls circadian transcription within the positive limb of the mammalian circadian oscillator. Cell 110: 251-260.

Raj A, Peskin CS, Tranchina D, Vargas DY, Tyagi S. 2006. Stochastic mRNA synthesis in mammalian cells. PLoS Biol 4: e309.

Ralph MR, Foster RG, Davis FC, Menaker M. 1990. Transplanted suprachiasmatic nucleus determines circadian period. Science 247: 975-978.

Ramsey KM, Yoshino J, Brace CS, Abrassart D, Kobayashi Y, Marcheva B, Hong HK, Chong JL, Buhr ED, Lee C, et al 2009. Circadian clock feedback cycle through NAMPTMediated NAD ${ }^{+}$biosynthesis. Science 324: 651-654.

Reddy AB, O'Neill JS. 2011. Metaclocks. EMBO Rep 12: 612.

Reddy AB, Karp NA, Maywood ES, Sage EA, Deery M, O'Neill JS, Wong GK, Chesham J, Odell M, Lilley KS, et al. 2006. Circadian orchestration of the hepatic proteome. Curr Biol 16: $1107-1115$.

Reinke H, Saini C, Fleury-Olela F, Dibner C, Benjamin IJ, Schibler U. 2008. Differential display of DNA-binding proteins reveals heat-shock factor 1 as a circadian transcription factor. Genes Dev 22: 331-345.

Reischl S, Kramer A. 2011. Kinases and phosphatases in the mammalian circadian clock. FEBS Lett 585: 1393-1399.
Reischl S, Vanselow K, Westermark PO, Thierfelder N, Maier B, Herzel H, Kramer A. 2007. Beta-TrCP1-mediated degradation of PERIOD2 is essential for circadian dynamics. J Biol Rhythms 22: 375-386.

Rosbash M. 2009. The implications of multiple circadian clock origins. PLoS Biol 7: e62.

Rutter J, Reick M, Wu LC, McKnight SL. 2001. Regulation of clock and NPAS2 DNA binding by the redox state of NAD cofactors. Science 293: 510-514.

Shearman LP, Zylka MJ, Weaver DR, Kolakowski LF Jr, Reppert SM. 1997. Two period homologs: Circadian expression and photic regulation in the suprachiasmatic nuclei. Neuron 19: $1261-1269$.

Shigeyoshi Y, Taguchi K, Yamamoto S, Takekida S, Yan L, Tei H, Moriya T, Shibata S, Loros JJ, Dunlap JC, et al. 1997. Light-induced resetting of a mammalian circadian clock is associated with rapid induction of the mPer1 transcript. Cell 91: $1043-1053$.

Siepka SM, Yoo SH, Park J, Song W, Kumar V, Hu Y, Lee C, Takahashi JS. 2007. Circadian mutant Overtime reveals F-box protein FBXL3 regulation of cryptochrome and period gene expression. Cell 129: 1011-1023.

Silver R, LeSauter J, Tresco PA, Lehman MN. 1996. A diffusible coupling signal from the transplanted suprachiasmatic nucleus controlling circadian locomotor rhythms. Nature 382: $810-813$.

Stokkan KA, Yamazaki S, Tei H, Sakaki Y, Menaker M. 2001. Entrainment of the circadian clock in the liver by feeding. Science 291: 490-493.

Sun ZS, Albrecht U, Zhuchenko O, Bailey J, Eichele G, Lee CC. 1997. RIGUI, a putative mammalian ortholog of the Drosophila period gene. Cell 90: 1003-1011.

Suter DM, Molina N, Gatfield D, Schneider K, Schibler U, Naef F. 2011. Mammalian genes are transcribed with widely different bursting kinetics. Science 332: 472-474.

Vanselow K, Kramer A. 2007. Role of phosphorylation in the mammalian circadian clock. Cold Spring Harb Symp Quant Biol 72: $167-176$

Vay L, Gu C, McNaughton PA. 2011. The thermo-TRP ion channel family: Properties and therapeutic implications. Brit $J$ Pharmacol doi: 10.1111/j.1476-5381.2011.01601.x.

Virshup DM, Eide EJ, Forger DB, Gallego M, Harnish EV. 2007. Reversible protein phosphorylation regulates circadian rhythms. Cold Spring Harb Symp Quant Biol 72: 413-420.

Welsh DK, Yoo SH, Liu AC, Takahashi JS, Kay SA. 2004. Bioluminescence imaging of individual fibroblasts reveals persistent, independently phased circadian rhythms of clock gene expression. Curr Biol 14: 2289-2295.

Welsh DK, Takahashi JS, Kay SA. 2010. Suprachiasmatic nucleus: Cell autonomy and network properties. Annu Rev Physiol 72: 551-577.

Yamazaki S, Numano R, Abe M, Hida A, Takahashi R, Ueda M, Block GD, Sakaki Y, Menaker M, Tei H. 2000. Resetting central and peripheral circadian oscillators in transgenic rats. Science 288: 682-685.

Yoo SH, Yamazaki S, Lowrey PL, Shimomura K, Ko CH, Buhr ED, Siepka SM, Hong HK, Oh WJ, Yoo OJ, et al. 2004. PERIOD2::LUCIFERASE real-time reporting of circadian dynamics reveals persistent circadian oscillations in mouse peripheral tissues. Proc Natl Acad Sci 101: 5339-5346.

Zschoernig B, Mahlknecht U. 2008. SIRTUIN 1: Regulating the regulator. Biochem Biophys Res Commun 376: 251-255. 


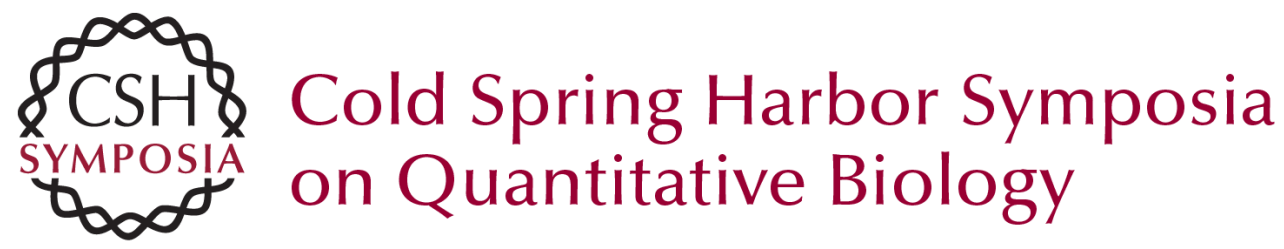

\section{The Mammalian Circadian Timing System: Synchronization of Peripheral Clocks}

C. Saini, D.M. Suter, A. Liani, et al.

Cold Spring Harb Symp Quant Biol 2011 76: 39-47 originally published online December 16, 2011

Access the most recent version at doi:10.1101/sqb.2011.76.010918

References This article cites 85 articles, 28 of which can be accessed free at: http://symposium.cshlp.org/content/76/39.full.html\#ref-list-1

\section{License}

Email Alerting Receive free email alerts when new articles cite this article - sign up in Service the box at the top right corner of the article or click here. 